that the import of some of these " communications" was far from friendly or generous on Mr. Syme's part towards myself.

I shall, for the present, pass over various irrelevant allusions in Mr. Syme's letter, and contentedly let them remain for their exact value. If that is to be estimated by the same standard as his observations on the subject to which my paper is devoted, it must indeed be small. He evidently does not understand the subject in discussion between my three friends and myself, and interposes a gratuitous description of the method in which Mr. Liston held his knife, for which there is no authority, either from these gentlemen or from Mr. Liston himself, who nowhere states that he held the point of his right finger against the cutting margin of the knife, even at the part where it was blunted; nor do the various illustrations to which I have objected show such an attitude.

No one can overlook or mistake the spirit which pervades Mr. Syme's letter. I have now, Sir, for seven years submitted in silence to a long list of professional calumnies from $\mathrm{Mr}$. Syme's mouth and pen. I have been unwilling to associate my humble name with squabbles and personalities, which are discreditable alike to individuals and to the profession. I have looked with contempt upon the many opprobrious epithets which have been applied to my public professional character, from a consciousness that they were beneath my notice, and that they came from one who had quarrelled with almost every friend he erer had, and who by law, and by a jury of his fellow citizens, has been proclaimed a libeller.*

In the army, when language is used "unbecoming an officer and a gentleman," short work is made with the delinquent. Why should not a similar rule apply to the medical profession? I might call on you, Sir, to interpose your high ethical autho. rity, when a professor talks - in language which one would suppose had come from Kansas instead of modern Athens-of " running a knife into the bowels of a living man ;" but, whatever further provocation Mr. Syme may throw in my way, I sincerely trust that no consideration will induce me to alter the course which I have hitherto followed.

I have the honour to be, Sir, yours, \&c.

George-street, Hanover-square, Nov. 1856.

WM. Fergusson.

To the Editor of THE LANCET.

SrR,-Mr. Fergusson, in pointing out the error in the illustration in Liston's "Surgery," as to the mode of holding the knife in lithotomy, has performed a graceful act of gratitude and justice towards the late Mr. Liston. He has spared posterity misconception and confusion on this point, and it will now be known that the illustration exhibits the knife in a position in which Mr. Liston never held it. I cannot, however, help observing, that Mr. Fergusson, in discharging this duty, has been far more elaborate than the occasion required. I also think, Sir, it will be perceived that he has claimed for $\mathrm{Mr}$ Liston a priority or originality to which he was not entitled. Mr. Fergusson says, "the operation of lithotomy, as at present performed in Great Britain and the colonies, is in a great measure founded on the example and doctrines of this distin guished surgeon." Hence we might infer, that in lithotomy there was something essentially differing from common in the " $\mathrm{ex}$ amples and doctrines" of Mr. Liston; whereashe really held the knife only as all other surgeons did, and made his incisions in the same manner. Whoever has seen the late Messrs. Key, Morgan, and $B$. Cooper lithotomize, must have observed that, as regards holding the knife and making the incisions, Mr. Liston's operation did not differ from theirs. I should be sorry to be understood as wishing to detract from the fame of a surgeon so justly great as the late Mr. Liston. I am only desirous that a special merit should not be claimed exclusively for Mr. Liston, which equally belongs to all surgeons who were his contemporaries, and even to many of preceding generation.

London, Oct. 1856. am, Sir, your obedient servant, AN OID GuY's Dresser.

\section{BLACK URINE FROM THE ADMTNISTRATION OF CREOSOTE.}

[LETTER FROM DR. HUGHES.]

To the Editor of THe LANCET.

Srr, - In a postscript to my "Select Cases," including "Cases of Black Urine from the Administration of Creosote," in the last volume of the "Guy's Hospital Reports," the following sentences occur:- "While these pages are at press, I have a

* Sce ease, Glover $v$. Syme, in the Edinburgh papers of the day. 524 man under my care in the hospital, in whom the urine is ren dered of a black colour when boiled with nitric acid. A further analysis shows this condition to be due to iodine, and it need scarcely be said that the patient is taking this remedy internally. To a similar cause, no doubt, must be referred the dark urine in the case of enema I mentioned at page 56, who was also under the same treatment."

"Time dose not allow me to put this explanation to the proof by testing the urine in other cases of patients who are taking iodine; but I have little doubt that it is the correct one - that is, that this medicine probably produces this change under certain conditions of disease."

Seeing that, in a brief notice of the "Guy's Hospital Reports" in THE LANCET of October 25th, the former of these two sentences is quoted, I think it justice to you, Sir, and to the profession at large, that the opinion therein expressed-an opinion derived from pretty decisive statements of one of my colleagues, and apparently supported by the fact of both of the patients having been taking iodine at the time-is a mistaken one. It is true, indeed, that urine containing iodine, by boiling with nitric acid, becomes of a dark colour; but this is an entirely different thing from the black soot-like deposit which existed in the two cases referred to. In the latter instance it soon disappeared, and never appeared again, although he con tinued the same medicine. The urine of several patients who were taking iodine, submitted to the same tests, did not yield a similar deposit. Upon what it did depend, I am at present in entire ignorance-an ignorance which neither the chemists nor the microscopists to whom I have applied are able to dispel.

I have the honour to be, Sir, yours respectfully, St. Thomas's-street, Nov. 1856. H. M. Hughes.

\section{ON THE NATURE OF PHTHISIS. [LETTER FROM DR. EDWARD SMITH.] \\ Tho the Editor of THE LANCET.}

SrR,-Considering the inconceivable importance to the community of any views of the nature of phthisis which give reasonable promise of diminishing the prevalence of that dis. ease, I venture to ask your permission to correct a few statements of my views, contained in your report of the discussion on iny paper on Saturday last.

1st. - Dr. Andrew Clarke considers that my theory would make phthisis a local disease. I believe it to be so far local, that its essential action on the lungs (that without which there could be no tubercular deposition) is a lessened inspiratory action of the air-cells. But this must be due to yet anterior conditions, and in chronic phthisis I believe them to be such as act through the general system-viz., whatever tends to exhaust the system, whether by exercise or defective action of any of the bodily or mental functions, the only peculiarity, so far, in my theory is, that I consider all these universally acting causes have one common mode of inducing the disease of the lung. But from a consideration of the structure of the air-cells, their supply of nerrous power, and their importince in the economy, it is highly probable that they have their own disease induced locally; and in acute phthisis, as also sometimes in chronic phthisis, there is evidence to show the high probability of a local origin. I consider that far too little is at present known of the diseases to which the air-cells are liable.

2nd.-In reply to the statement that leucothyæmia, as well as an alteration in the tone of some of the discs, and certain free molecules are found in phthisis, I would reply that the nature of the disease must not be determined by its co-ordinate circumstances, but by those which always attend its origin. The blood must become changed in the course of the disease, and may be changed before the origin of it, and yet not be cansative of it. Moreover, lencothyæmia, if it occur, (as I think it highly probable,) would not be peculiar to a distinction of phthisis, neither would a knowledge of that fact lead to any better views of the nature and treatment of that disease.

3rd.-The coincidence of scrofula and phthisis, and the alleged interchange of the two diseases in members of the same family, would not be evidence that they were essentially the same disease, much less that they would be necessarily causative of each other. It is easy to admit that the two diseases do occur together; but it is equally easy for me to prove that phthisis will occur without the scrofula, either in the patient himself or in his family, and that the contrary is found in only a very small proportion of the cases attending my practice at the Hospital for Consumption. I believe that the two diseases often result from similar causes-viz., a certain original pecu- 